\title{
On the mechanism of three-body adhesive wear in turning
}

\author{
Inge Svenningsson ${ }^{1}$ (D) $\cdot$ Kourosh $\operatorname{Tatar}^{2}$ (D)
}

Received: 14 December 2020 / Accepted: 24 February 2021 / Published online: 4 March 2021

(C) The Author(s) 2021

\begin{abstract}
The paper reveals a hypothesis regarding the adhesive mechanism in metal cutting and its mechanical dynamics. One steel grade, 34CrNiMo 6, $285 \mathrm{HB}$, and one set of coatings on the cutting tool are reviewed. The adhesive mechanism is a transient vibration, including a feedback system limited by the plastic deformation in the chip. The vibration shows as a cluster of waves with stochastic duration in time. It starts up again after a stochastic lapse of silence. The cycle frequency is around $12.5 \mathrm{kHz}$ and the internal excitation is twice that frequency, as the cutting speed and feed are $200 \mathrm{~m} / \mathrm{min}$ and $0.2 \mathrm{~mm}$, respectively. The adhesive frequency and amplitude are influenced by the cutting speed and the current wear status. The adhesion is monitored by the sound waves emanating from vibrations in the chip, the part still in the workpiece.
\end{abstract}

Keywords Adhesive wear $\cdot$ Turning $\cdot$ Frequency $\cdot 34$ CrNiMo 6

\section{Introduction}

Adhesion is one of the main wear mechanisms in metal cutting [1]. It shortens the tool life and can have a devastating impact on the machined surface quality. Worn cutting edges affect the surface finish, integrity, flatness [1,2], and the cutting forces [1]. For example, the flatness deviation in milling is flank wear dependent [3]. The demands of the surface integrity are often the main reason for the use of coolant and lubrication of the cutting zone. The negative effect of adhesion can be reduced by providing lubrication between the chip and the cutting tool/ the workpiece and the cutting tool. The topography of a machined surface after turning of carbon steel by three different cooling and lubrication methods, minimum quantity cooling lubrication, minimum quantity cooling lubrication with extreme pressure and anti-wear additives $(\mathrm{MQCL}+\mathrm{EP} /$ $\mathrm{AW}$ ), and minimum quantity lubrication was investigated and compared to dry machining in Ref. [4]. All cutting tests were conducted using coated cemented carbide tools. According to

Kourosh Tatar

kourosh.tatar@hig.se

Inge Svenningsson

inge.svenningsson@ driscg.com

Driscg, N. Hasselgatan 15, 81135 Sandviken, Sweden

2 Department of Industrial Management, Industrial Design and Mechanical Engineering, University of Gävle, Gävle, Sweden the authors, the best surface features were obtained using MQCL + EP/AW method, indicating sufficient lubrication conditions in the tool-workpiece interface The best machined surface was "characterized by the most uniform distribution of peaks and valleys" and the best lubrication condition was an evenly distributed thin layer of tribofilm on the machined surface. A comprehensive review on cutting fluids and cooling techniques can be found in Ref. [5]. Most of the lubricating substances have environmental or health concerns; they are also a substantial part of the production cost. Dry machining is desirable from these aspects but not easy to perform.

The understanding and the control of the adhesive mechanism are essential for the optimization of metal cutting processes in the manufacturing industries. The adhesive mechanism is also a candidate for the monitoring of the cutting process.

Adhesive wear occurs when two solids are in sliding contact and the atomic bonding forces occurring between the materials on the interface are stronger than the strength of the surrounding area in either of the materials [6]. Considerable adhesive tool wear may also co-occur with built-up edge (BUE) formation [1]. If the adhering of parts of the material to the cutting edge, as in the formation of BUE, is sufficiently stable, the adhered layer can protect the cutting edge and extend its lifetime. However, if the adhered layer is unstable and frequently removed, this leads to adhesive wear. By changing the surface topography of the tool, the adhesion, and the stability of BUE formation changes, which 
in turn affect the corner radius wear and the wear on the flank side [7]. In Ref. [8] the effect of different tool surface textures on adhesive wear on the rake face was investigated. Apparently, the presence of specific fabricated micro and nano-scaled textures reduced the adhesive wear.

Much research, for example $[9,10]$, focuses on the influence of cutting parameters on tool wear and tool life prediction using design of experiments. Usually, the cutting speed has the foremost effect on tool life, as shown in $[9,10]$. Furthermore, in Ref. [11], the effect of cutting parameters under the application of minimum quantity coolant was studied. The cutting speed was the most important parameter, and adhesive wear was the main wear mechanism at cutting speeds of about $200 \mathrm{~m} / \mathrm{min}$.

Another factor that influences adhesive wear is the tool material $[1,12]$. The adhesive wear resistance of carbide composite tools depends on carbide volume fraction, carbide, and binder material [13]. Generally, the increase in the volume fraction of the carbide improves the adhesive wear resistance.

Steels and cast irons are often machined using coated cutting tools, where the coatings are to increase the wear resistance of the cutting edge. The type of employed coating varies with the work material, tool material, and type of machining application. In Ref. [12], tool wear during grooving of spheroidal cast iron was investigated. It was shown that the coefficient of friction between the rake face and the flowing chip was lower, and less sensitive to cutting speed and feed, for coated Boron Nitride Dispersed Cemented Carbide tools, compared to uncoated ones. In addition, the BUE formation and adhesive were was less intense for the coated tools. In general, cutting forces, vibration amplitudes, BUE formation, and wear increased with cutting speed.

The mechanism of adhesive wear is not fully understood, like many other processes in the cutting zone. It is difficult to study since the cutting tool and workpiece material are not transparent. The speed of the mechanism is also a problem; a cycle is often over $10 \mathrm{kHz}$ and its fractions quicker than that. One possible approach is to examine the workpiece and the chip before and after the adhesion, and study measured signals emanating from the adhesive mechanism like sound, vibration, radiation, acoustic emission, and gases (smell). Simulation, fast Fourier transform (FFT), and more hands-on theoretical work are often necessary tools to fulfill the task. For example, in Ref. [14], burst-type acoustic emission signals have been correlated to the adhesive wear mechanism, in a socalled pin-on-block type friction tester, and also in Ref. [15], the wear rates and wear mechanism of a metal alloy were studied by tribological (pin-on-block) experiments. By using frequency analysis of measured force signals, different tribological properties could be correlated to the amplitudes and frequencies of the detected signals.

A typical adhesive wear pattern resembles "caries in a tooth." It appears between the abrasive zone and the stagnation zone, near the cutting edge; see Fig. 1. These adhesive cavities often cause chipping of the edge; see Fig. 2. The wear pattern usually cannot be seen by the naked eye since the size of the cavities is often too small, and not enough light is scattered from the area. The cavities are also filled with $\mathrm{SiO}$ or other substances with a lower melting point than iron if the work material is steel. Most workshop operators do not realize how to face this problem; they just observe that the tool is worn out.

This paper deals with adhesion in metal cutting and only focused on:

- adhesion on the rake face of the cutting tool in turning;

- one type of work material, i.e., EN 34CrNiMo 6 steel with a Brinell hardness of about 285, not calcium treated, relatively large $\mathrm{Al}_{2} \mathrm{O}_{3}$ inclusions (6-8 $\mu \mathrm{m}$ is present);

- one type of cutting tool, i.e., $\mathrm{Al}_{2} \mathrm{O}_{3}$ coated carbide inserts. Other coatings are present underneath the top coating(TiC, TiN, and TCN) but it is assumed that they do not interfere; and

- dry machining, feed, speed, and cutting depth in line with what are used in everyday production.

The paper aims to verify the presented hypothesis, a novel model describing the physical mechanism that produces adhesive wear in turning. Further novelty in this paper lies in this application of the model and its combination with the chosen measurement method, i.e., that the adhesion is studied by sound waves emanating from vibrations in the chip.

\section{The adhesion hypothesis}

The traditional model for adhesive wear [16, 17], where a protuberance on one side meets a similar on the other side and then causes plastic deformation and welding, is not applicable in metal cutting. In the current steel, also in many other work materials, there is a third component between the chip and the cutting tool, a viscous substance containing $\mathrm{SiO}$ and other materials with lower melting temperature than steel. This substance is welded to the chip and on the rake of the tool in the adhesive cycle. Together forms three-body adhesive wear.

The adhesive mechanism consists of a sequence of events. In this hypothesis, they are defined as follows:

- Degeneration of the surface in what will be the adhesive zone.

- The chip weld on to the cutting tool.

- The adhesive cycle.

Aluminum oxide and iron do not stick together. When a sample of $34 \mathrm{CrNiMo} 6$ has been polished, the $\mathrm{Al}_{2} \mathrm{O}_{3}$ 
Fig. 1 The adhesive, the abrasive, and the stagnation zones

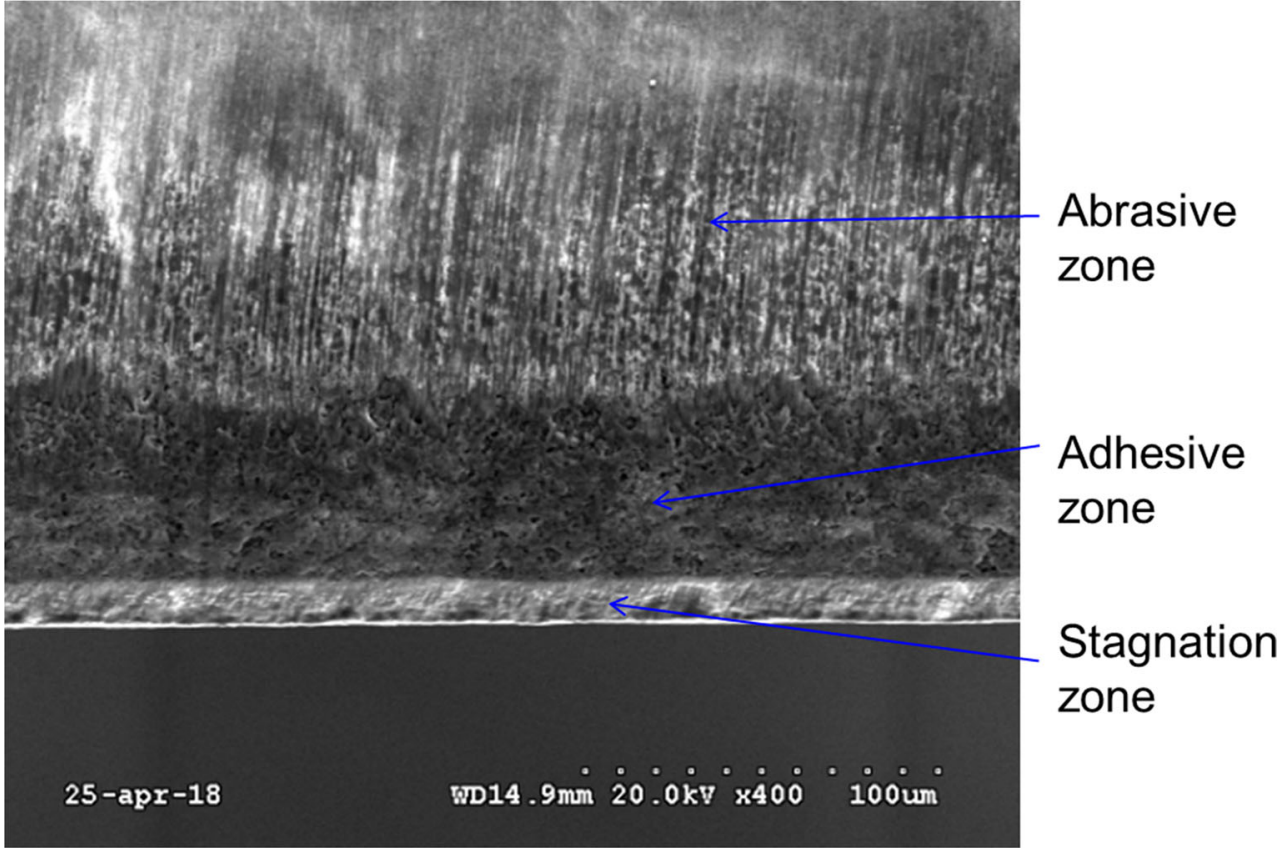

inclusions often fall out. A change of the conditions on the cutting tool surface is thus necessary before it can weld on to the chip. The environment, see Fig. 3, between the chip and the rake surface of the cutting tool, consists of liquid or half liquid substances mixed up with iron. The main part is $\mathrm{SiO}$, $\mathrm{MnS}$, and Fe but many other substances can occur since metal scrap is used as raw material, both in scrap-based and in most ore-based steel production.

Aluminum oxide and silicon oxide are found in nature as kaolinite clay while heated up above $550^{\circ} \mathrm{C}$, forming metakaolinite, $\mathrm{Al}_{2} \mathrm{Si}_{2} \mathrm{O}_{7}$ [18]. In this work, it is believed that a thin layer of the coating turns into metakaolinite or other complex oxides as a result of high temperature, high pressure, and extreme deformation of the $\mathrm{SiO}, \mathrm{MnS}$, and $\mathrm{Fe}$ compound. The idea is that this degenerated thin layer will make it possible for the rake of the chip to weld on to the cutting tool. The rake face of the chip consists of $\mathrm{SiO}, \mathrm{MnS}$, and $\mathrm{Fe}$ compound, above that likely retained austenite, further into the chip tempered martensite. The retained austenite expands more than tempered martensite and is, therefore, more present on the
Fig. 2 Chipping caused by excessive adhesive wear

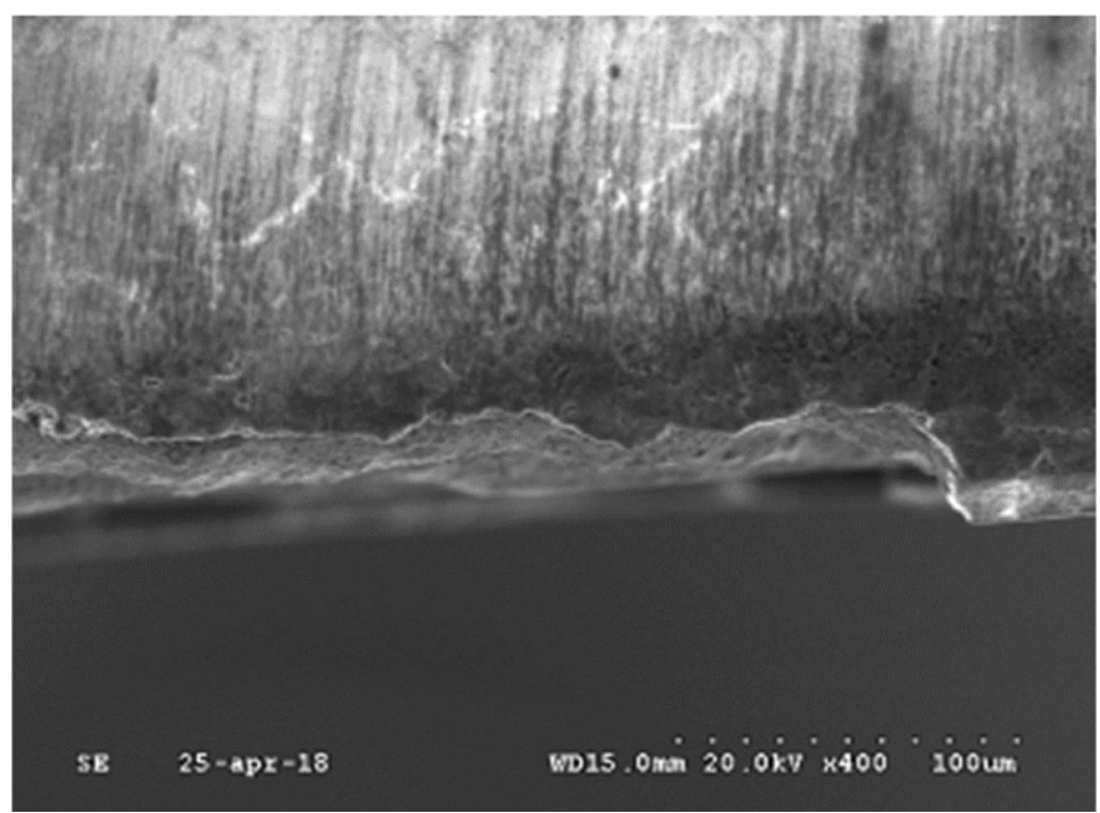


Fig. 3 The environment. (a) Between the chip and the rake surface are some liquid or half liquid substances. (b) Deposits, $\mathrm{SiO}, \mathrm{MnS}$, and others with a the cutting tool after machining, $\mathrm{Fe}$ is also present lower melting point than $\mathrm{Fe}$, on

\section{a}

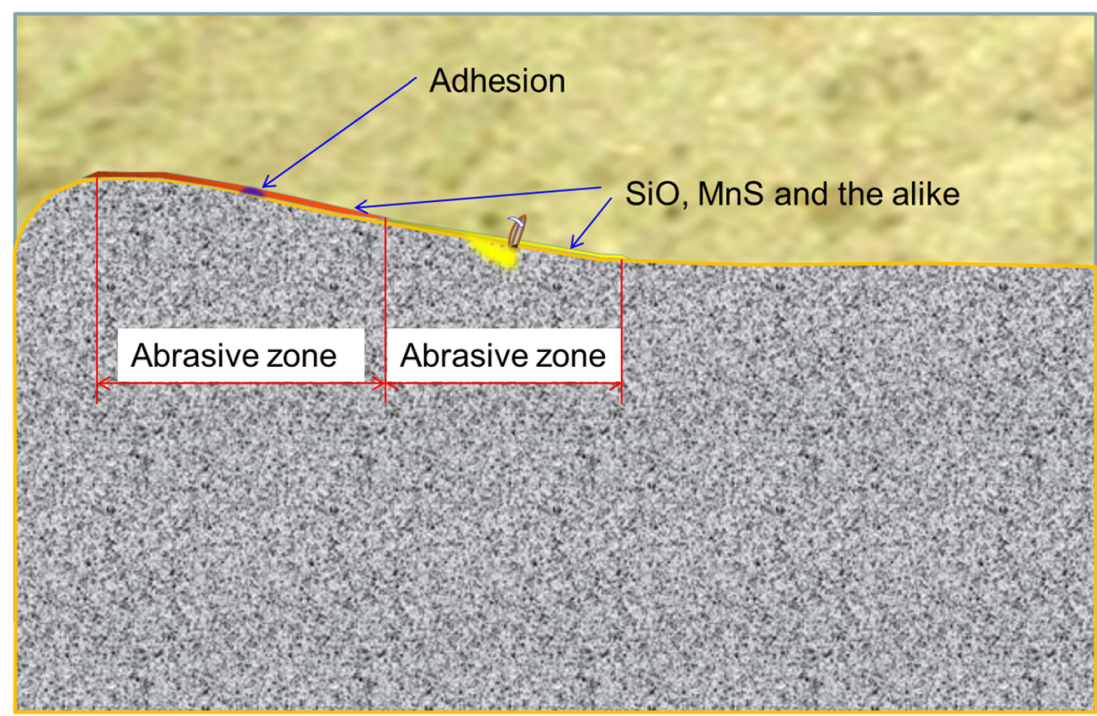

b

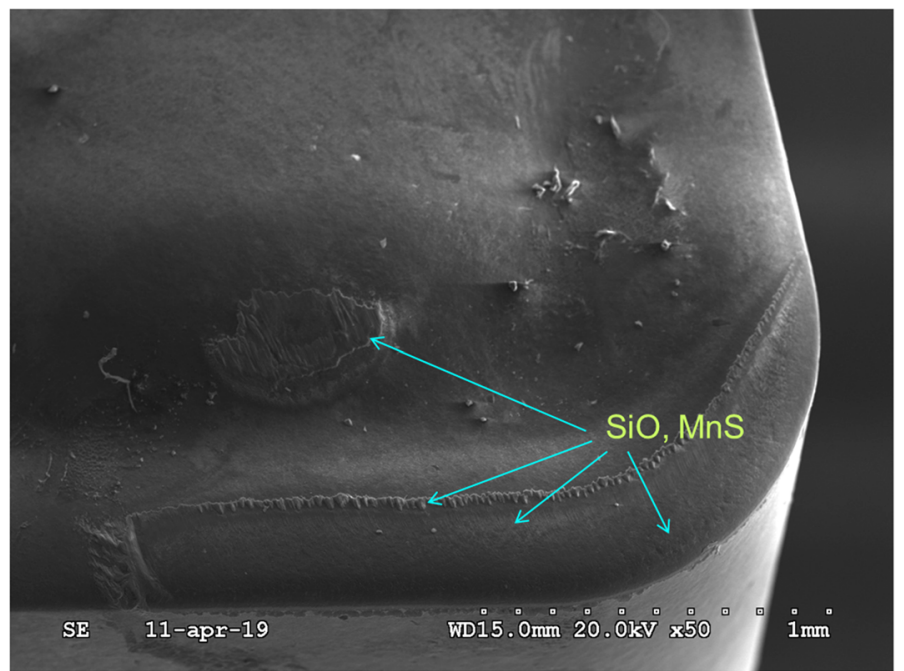

rake surface of the chip. If the coating changed from $\mathrm{Al}_{2} \mathrm{O}_{3}$ to another hard ceramic coating, the chemistry will be different, but the degradation of the surface remains. It is hard to find materials without adhesive interactions.

In this work, it is assumed that welding is possible when the two surfaces, the rake of the chip and the rake face on the cutting tool, are moving side by side with the same speed or standing still for a moment. It is likely a vibration that causes the zero relative movements; the vibration can be any vibration. It is likely the $\mathrm{SiO}$ and the metakaolinite that are welded together, Fig. 4.

The adhesive cycle consists of the following five steps:

1. When the welding is complete, the chip material press onto the welded area, and on the other side, the chip pulls the weld in the chip flow direction.
2. At the level when the strength of the weld is exceeded the chip rip of a thin layer of the cutting tool material. In this case, likely metakaolinite or similar.

3. The elastic deformation in the chip and the chip movement send the chip forwards in the chip flow direction. A dynamic half-sine movement, see Fig. 5.

4. At the end of the half-sine movement, it reaches the velocity $=0$. At this point, it welds again.

5. After relaxation, a further movement, it reaches its "neutral" shape.

This cycle is repeated several times, about $5-50$ or more cycles, manifested as a cluster of waves, and is then calm for a while. When it starts over again, it is probably on another spot while the degenerated layer in the previous spot is consumed. 
Fig. 4 The chip and the cutting tool are welded together

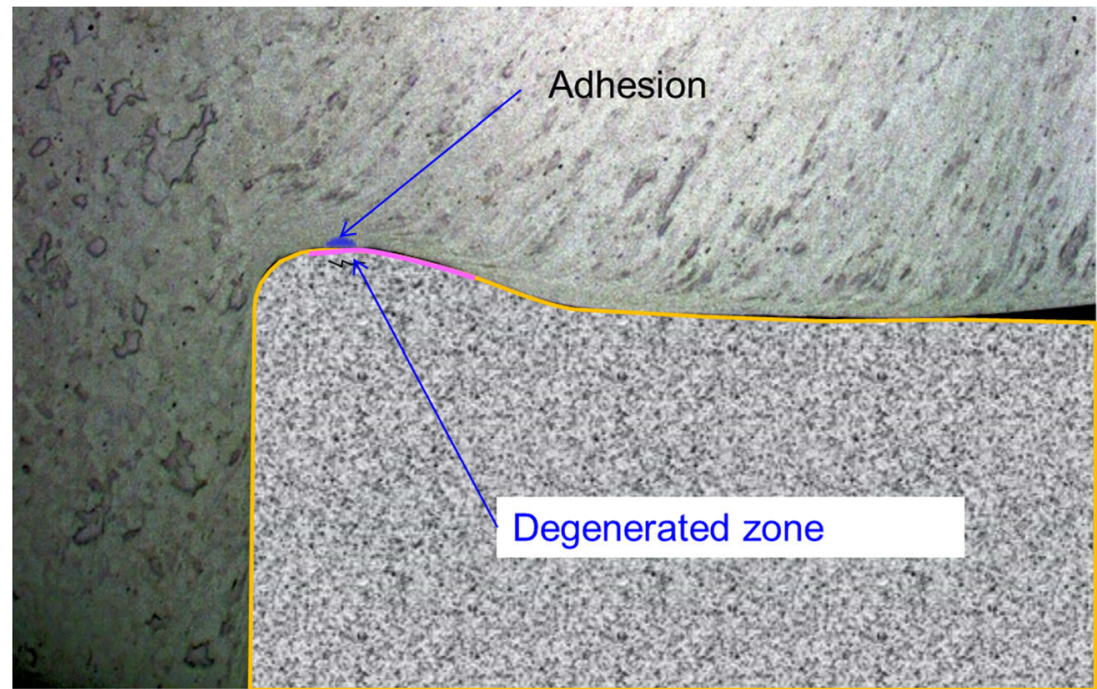

Another aspect of the adhesive mechanism in metal cutting is that it happens only once at a time on the rake of the cutting tool. If two areas are active simultaneously, they must be in phase and should then be regarded as one. Multiple adhesions out of phase would deform the chip and by that require additional force.

\section{Experimental procedures}

\subsection{Experimental approach}

Figure 6 is a photo showing the experimental set-up. The vibration from the cutting zone, mainly the chip vibration, was measured. The sound waves coming from the machine tool, also from elsewhere, were picked up by two Sennheiser type KE4-211-2 microphones and an A/D-converter. The sensitivity of the microphones was $10 \mathrm{mV} \mathrm{Pa}^{-1}$. In this study, it is believed that the measured waves will be distorted if they are picked up directly on the cutting tool or the machine tool chassis since waves go back and forth in the structure, like an echo.

The focus was on the frequency range above $10 \mathrm{kHz}$. The sound detected by the measuring microphone in this frequency range is generated by surfaces connected to relatively low masses, like a chip.

The cutting insert chosen for this experiment was a CVD coated cemented carbide, namely, Sandvik Coromant CNMG $120408-\mathrm{XM}$, rake angle $\gamma_{\mathrm{o}} \approx 8^{\circ}$, clearance angle $\alpha_{\mathrm{o}} \approx 7^{\circ}$, angle of inclination $\lambda_{\mathrm{s}}=-6^{\circ}$, grade 4325 . The coating material is $\mathrm{TiCN}+\mathrm{AL}_{2} \mathrm{O}_{3}+\mathrm{TiN}$.

EN 34CrNiMo 6 steel was used as workpiece material during the turning tests. 34CrNiMo6 is generally used for large axles, machine components, tools, and high strength
Fig. 5 The movement of the point $Q$ on the chip

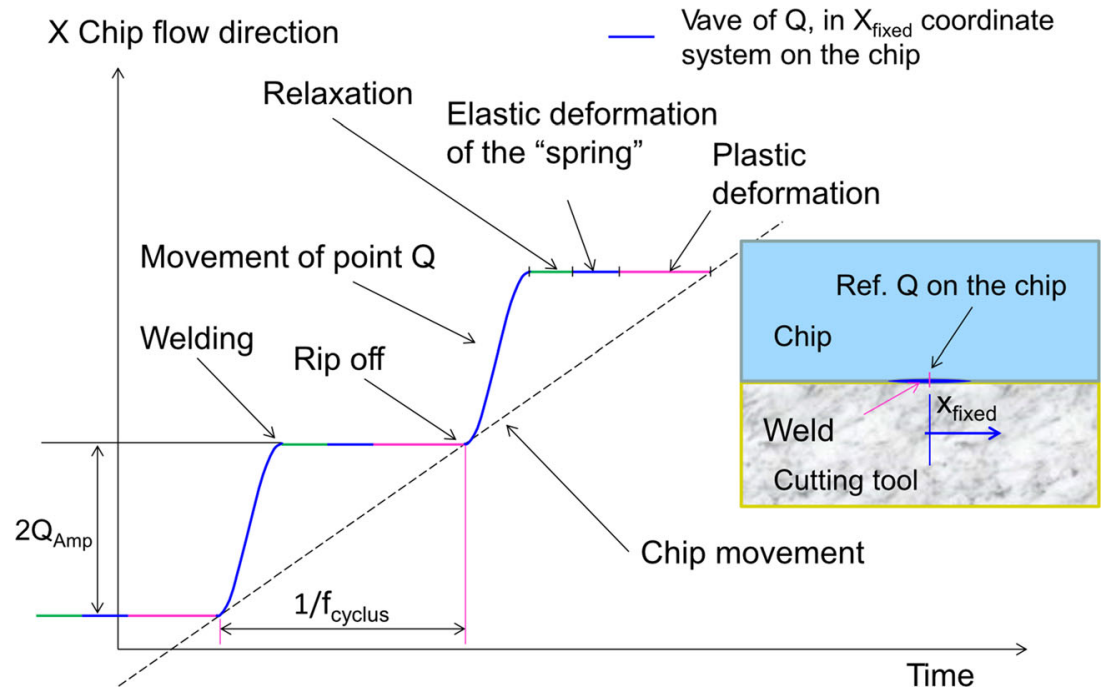


Fig. 6 Photo of the experimental setup applied in the test: (1) microphones, (2) turning tool, and (3) workpiece

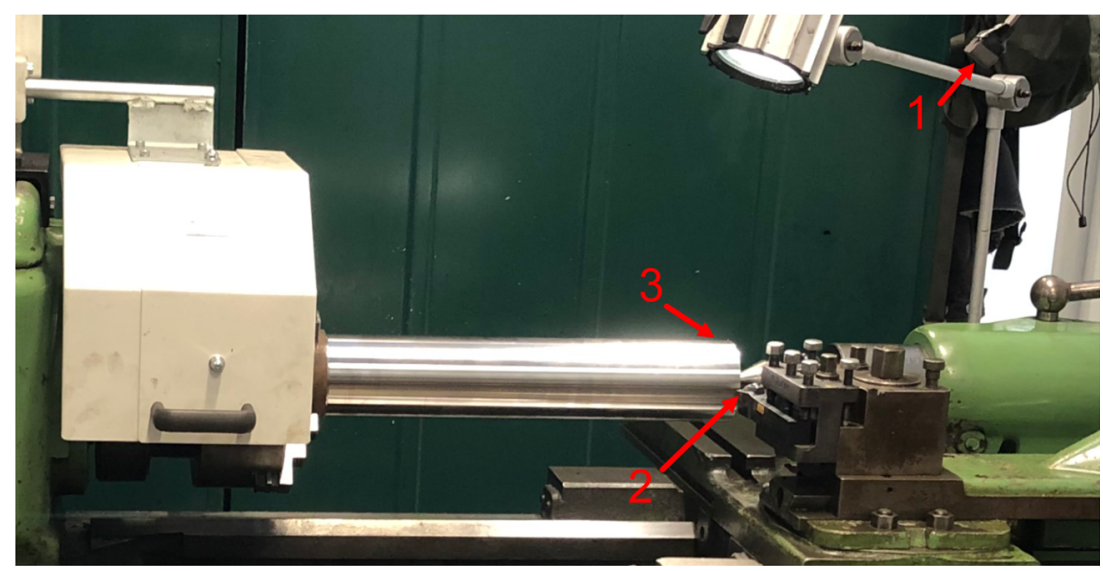

fasteners. This material contains relatively large $\mathrm{Al}_{2} \mathrm{O}_{3}$ inclusions. The larger ones are in the range of $1-10 \mu \mathrm{m}$, by volume 500-1000 ppm. The matrix material is tempered martensite and the average hardness is $285 \mathrm{HB}$. The chemical composition is given in Table 1. The producer is Ovako Imatra Oy, Finland.

Axial turning free from regenerative chatter was performed with a cutting speed $v_{c}=120-220 \mathrm{~m} / \mathrm{min}$. The feed and the depth of cut were set to $f_{n}=0.2 \mathrm{~mm} / \mathrm{rev}$ and $a_{p}=1 \mathrm{~mm}$, respectively. All cutting tests were conducted under dry conditions. About 120 million data samples were collected at a sampling frequency of $48 \mathrm{kHz}$.

A preliminary study [19] shows that the adhesion removes thin layers of material in each cycle. The thickness was found to be in the nanometer range. In those tests, sequentially machining was performed, $30 \mathrm{~s}$ at a time, and then, the cutting tool was cleaned in boiling $30 \% \mathrm{HCl}$, to remove $\mathrm{SiO}, \mathrm{MnS}, \mathrm{Fe}$, and so forth from the sample, before a photo of the sample was taken. The procedure was repeated until the edge was worn out. The result remains of reversed $3 \mathrm{D}$ printing.

Figure 7 shows an FFT of the microphone signal. The frequencies lower than $5 \mathrm{kHz}$ are related to the natural frequencies in the machine tool, the workpiece, and the cutting tool. In the current medium-sized lathe, it is rare with natural frequencies above $5000 \mathrm{~Hz}$ [20]. The segmentation frequency is $f_{\text {seg }}=10400 \mathrm{~Hz}$; see also micrograph in Fig. 8, and following calculations. The segmentation of the chip gives rise to a continuous signal. Data from Fig. 8, the average segment length is $0.16 \mathrm{~mm}$, with the chip ratio $r_{c}=2$ and cutting speed $v_{c}=200 \mathrm{~m} / \mathrm{min}$ gives the segmentation frequency of 10400
Hz. It is near the adhesive vibration but with lower amplitude and also different performance, and should therefore not interfere. Also, abrasive wear generates high-frequency vibrations, but they have a much higher frequency range, around 45 $\mathrm{kHz}$, in this material and current cutting speed [21]. Dislocation movements generate vibrations far beyond what we measure in this test. The conclusion is that the frequencies around $12.5 \mathrm{kHz}$ are the adhesive vibrations, $f_{\mathrm{Adh}}$, and that the frequencies around $14-18 \mathrm{kHz}$ are overtones caused by the interrupted adhesive process. The adhesive frequency together with the overtones forms the cluster of waves. In acoustics, a beat is an interference pattern between two sounds of slightly different frequencies. If we sum the main adhesive frequency and the overtones, we get a signal much like the measured and high pass filtered signal in Fig. 9. It is visible in Fig. 9 that the adhesive excitation can be continuous some cycles and then cease when the chip fails to weld on the tool.

There is also adhesive vibration on the cutting tool clearance. If this adhesion vibrates with the same frequency and in the same phase as on the rake side, it will be a small part of the measurements. If not, the amplitudes will be very small due to the differences in dynamic stiffness between the chip and the cutting tool/workpiece. The sound is depending on the size of the vibrating surfaces and their amplitudes. The cutting tool and the workpiece have large surfaces but small vibration amplitudes due to the high impedance in the current frequency range. However, no adhesive vibration (sound) from the clearance side could be identified.

The setup has two microphones and their signals have a phase shift in between them indicating that the sound comes from the "side" where the cuttings take place.

Table 1 Chemical composition of EN 34CrNiMo 6 steel (\%)

\begin{tabular}{lllllllr}
\hline $\mathrm{C}$ & $\mathrm{Si}$ & $\mathrm{Mn}$ & $\mathrm{S}$ & $\mathrm{Cr}$ & $\mathrm{Mo}$ & $\mathrm{Ni}$ & $\mathrm{Fe}$ \\
\hline 0.34 & 0.30 & 0.70 & $<0.035$ & 1.5 & 0.20 & 1.5 & Balance \\
\hline
\end{tabular}


Fig. 7 FFT of the measured sound from the machine tool. Amplitude (linear from the microphone in $\mathrm{mV}$ )

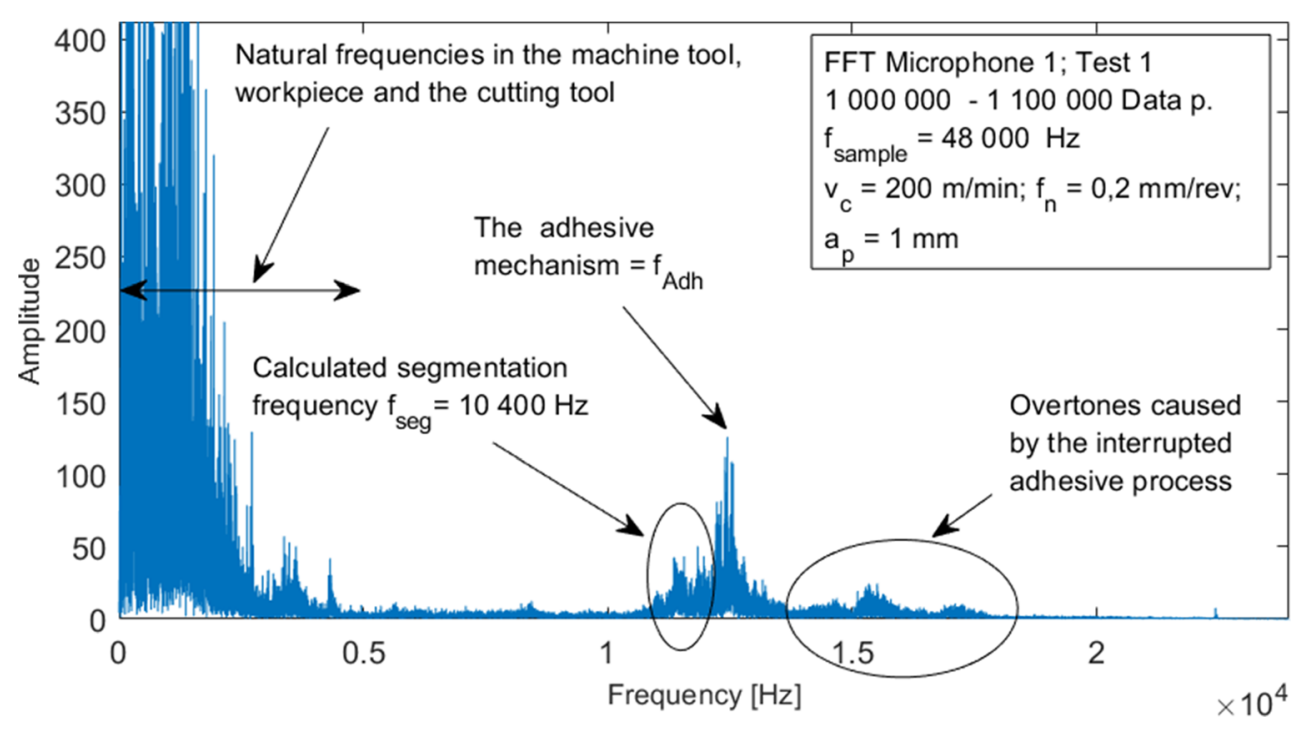

Further measurements with a Kistler dynamometer were performed. The main cutting force, measured in the tangential direction, shows belivably the adhesive vibration emanating from the clearance of the cutting tool; see Fig. 10. The vibration has a frequency of about $6250 \mathrm{~Hz}$, half of what was found from the rake of the tool when the chip vibrates. It has also the same type of stochastic behavior as the vibration on the rake. This makes sense. There is only "one" cutting zone, what happens on one side effects the other side, but the masses involved are different; hence, they find different frequency ranges for their masses, likely at multiplied frequencies.

\subsection{The adhesive cycle and its dynamics}

In steps, the following happens; see Figs. 11 and 12.

Elastic stresses around the welded point rip off the chip

1. The elastic "spring" and the movement of the chip behind push the chip in the chip flow direction.

2. Assume that new welding occurs when the sine movement of the chip reaches the velocity $=0$. Because of the chip flow, it has to exceed its maximum value. On the way back, at the point of about, $\approx Q_{\mathrm{amp}} \cdot \sin (3 \pi / 4)$, it has in the opposite direction, the same speed as the chip flow speed, designation, a, in Fig. 12. Then, the new welding can occur.
Fig. 8 The segmentation of the chip

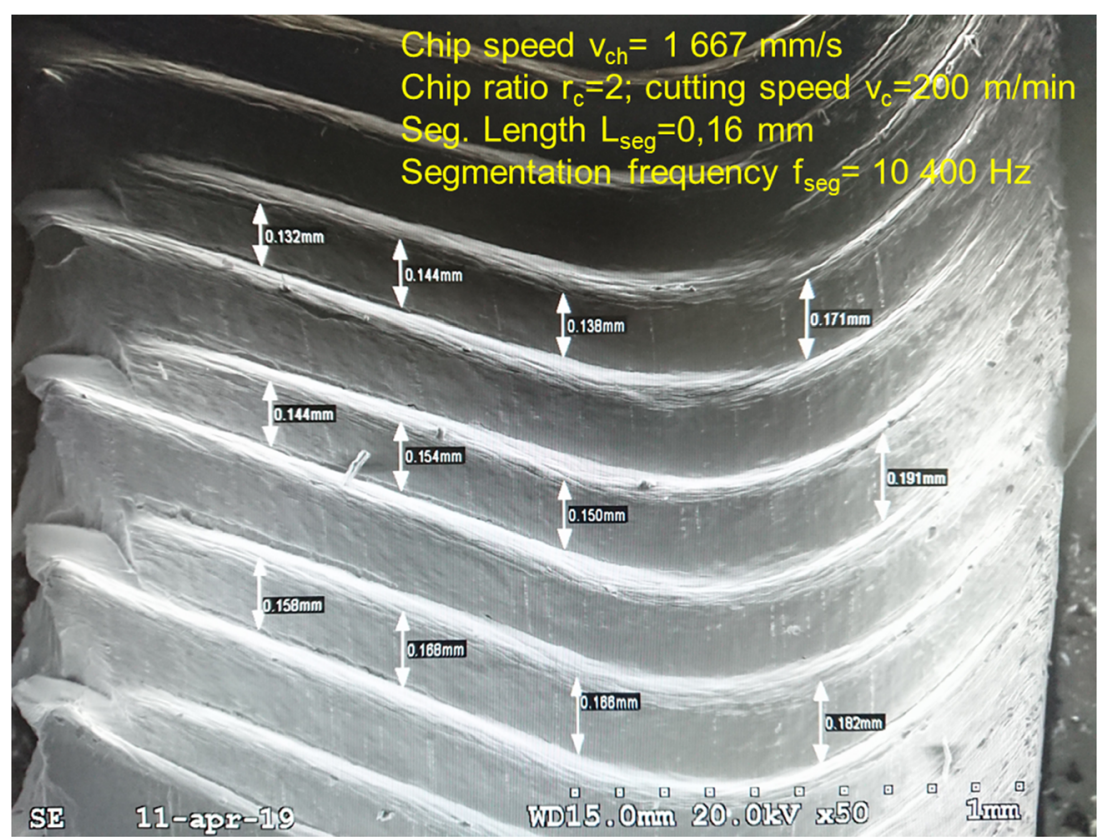


Fig. 9 High pass filtered signal. Amplitude (linear from the microphone in $\mathrm{mV}$ )

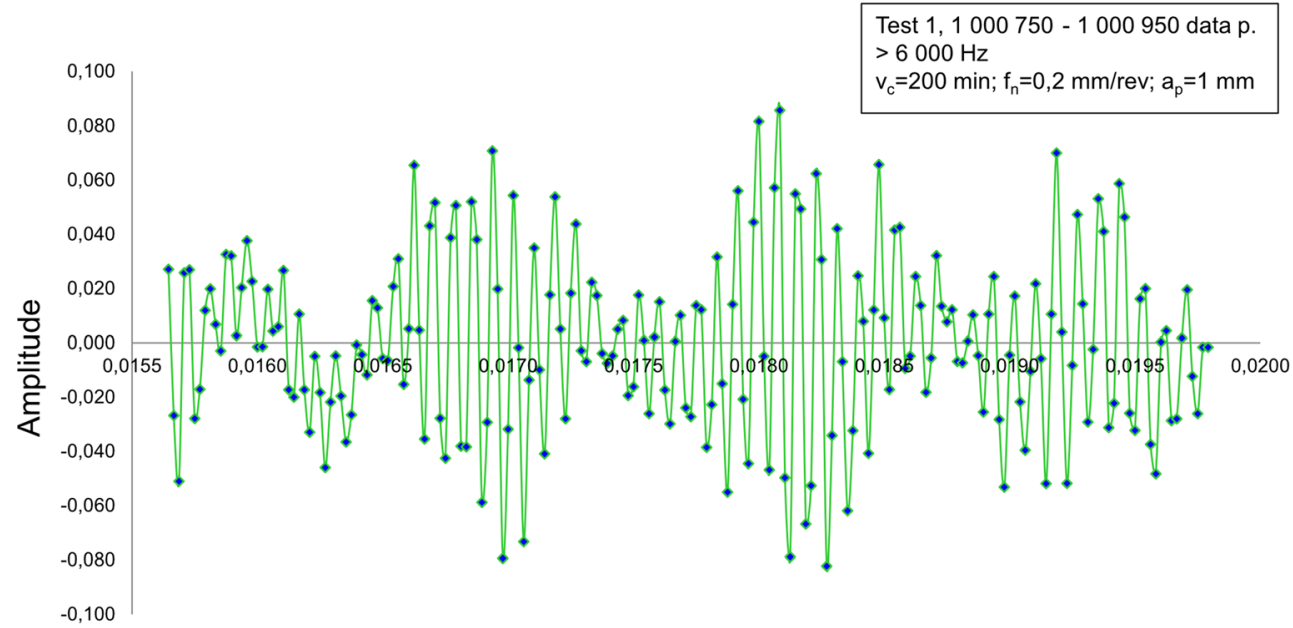

Time [s]
3. At the relaxation step, the material around the welding takes a more neutral stress configuration.

4. Elastic deformation, the "spring" is compressed.

5. Plastic deformation around the welding, this step is visible on the chip.

6. At this step, it "might" start over again.

The cycle time calculated from the measured adhesive frequency is:

1 cycle $=1 / f_{\text {Adh }}=80 \mu \mathrm{s}$

Assuming that the chip speed increases linear from the edge to where the plastic deformation ceases, and together with a known chip ratio of $r_{c}=2$, give:

$v_{\text {Chip }}=1833 \mathrm{~mm} / \mathrm{s}$ and $v_{\text {Adhesive zone }}=612 \mathrm{~mm} / \mathrm{s}$

The length of the plastic zone is $L_{p l} \approx 20 \mu \mathrm{m}$, Fig. 13, which implies that the time for the plastic deformation is $T_{\mathrm{pl}}=32,7$ $\mu \mathrm{s}$. This figure is not precise due to the difficulties to measure the deformation zone and that the material flow during the adhesion is likely more complex than assumed.

The adhesive mechanism is a dynamic system with a relative damping of, $\zeta=0,08$ (8\%). The figure is calculated from the measured data and is in the same range as for cutting tool movements or machine tool parts movement in general. The dynamic behavior makes the following assumption realistic:

$T_{\mathrm{el}}=T_{\text {rel }}=Q_{\text {cycle }} / 4$

where $T_{\text {el }}$ is time for elastic deformation, $T_{\text {rel }}$ is time for relaxation, and $Q_{\text {cycle }}$ is the cycle time for wave $Q$, and

$T_{\mathrm{pl}}+T_{\mathrm{el}}+T_{\text {rel }}+\frac{Q_{\text {cycle }}}{2}+2 \cdot \sin \left(\frac{\pi}{8}\right) \frac{Q_{\text {cycle }}}{2}=T_{\text {cycle }}$

Eq. (1) and (2) give:

$T_{\text {el }}=\left(T_{\text {cyclus }}-T_{\text {pl }}\right) /(1+1+2+0.765) \approx 10 \mu \mathrm{s}$

Eq. (1) and (3) give that the vibration $Q$ has a frequency of: $f_{Q}=1 /\left(4 T_{\mathrm{el}}\right)=25 \mathrm{kHz}$.

With the main adhesive frequency of, $f_{\mathrm{Adh}}=12.5 \mathrm{kHz}$, it is logical that the elastic wave has twice as high frequency, $f_{\mathrm{Q}}=$ $25 \mathrm{kHz}$. It seems to be so that the frequencies $f_{\mathrm{Adh}}$ and $f_{\mathrm{Q}}$ are depending on the stiffness in the small chip stump coming from the workpiece and the masses involved, the mass of the stump, and some more of the chip sticking out from the stump.
Fig. 10 Main cutting force Fc, measured in the tangential direction with a Kistler dynamometer

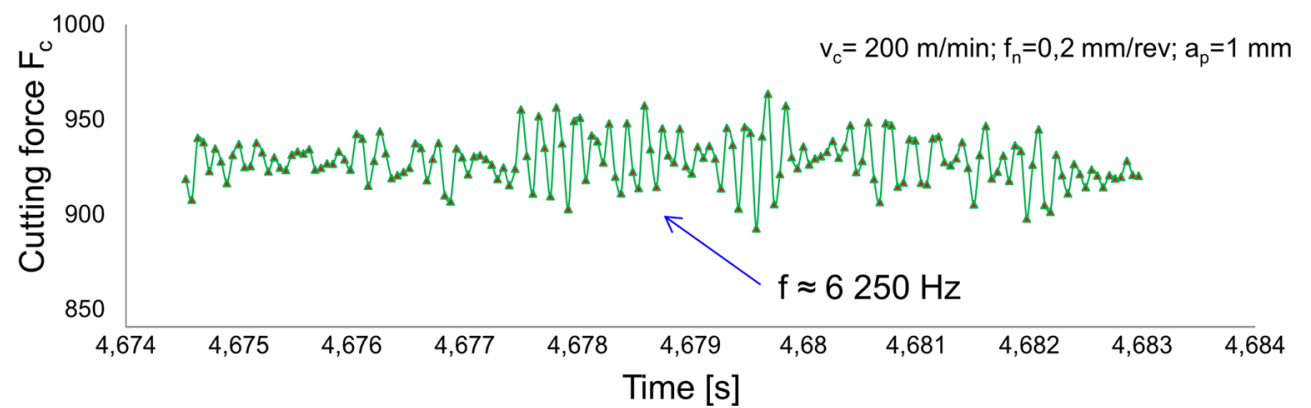


Plastic \& elastic def.

Swing

Relaxation

Sum
$42,8 \mu \mathrm{s}$

$27,2 \mu \mathrm{s}$

$10,0 \mu \mathrm{s}$

$80 \mu \mathrm{s}$
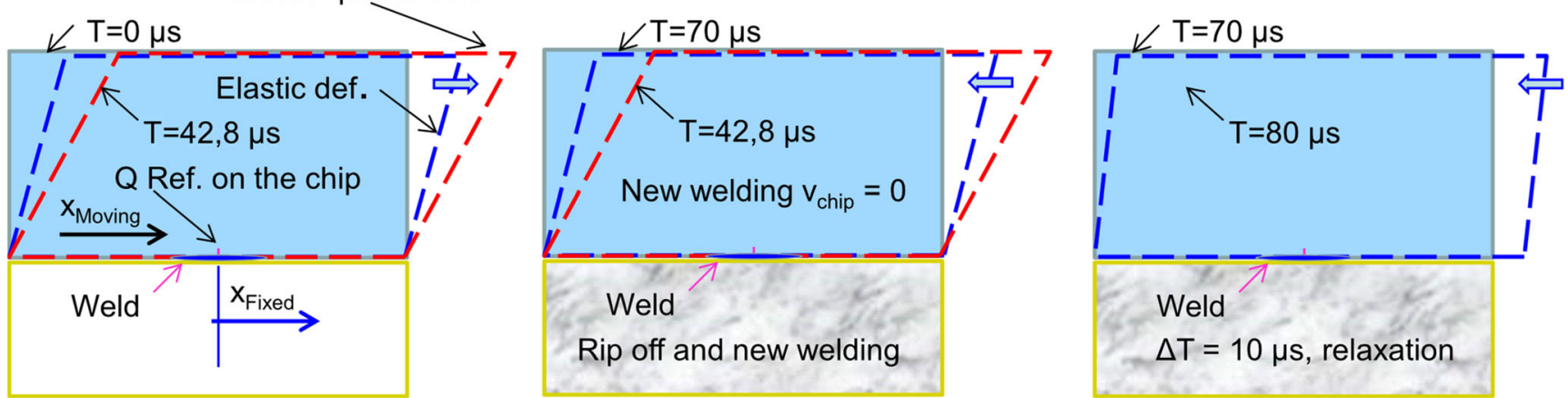

Fig. 11 The adhesive cycle step by step

Fig. 12 The dynamic adhesive system

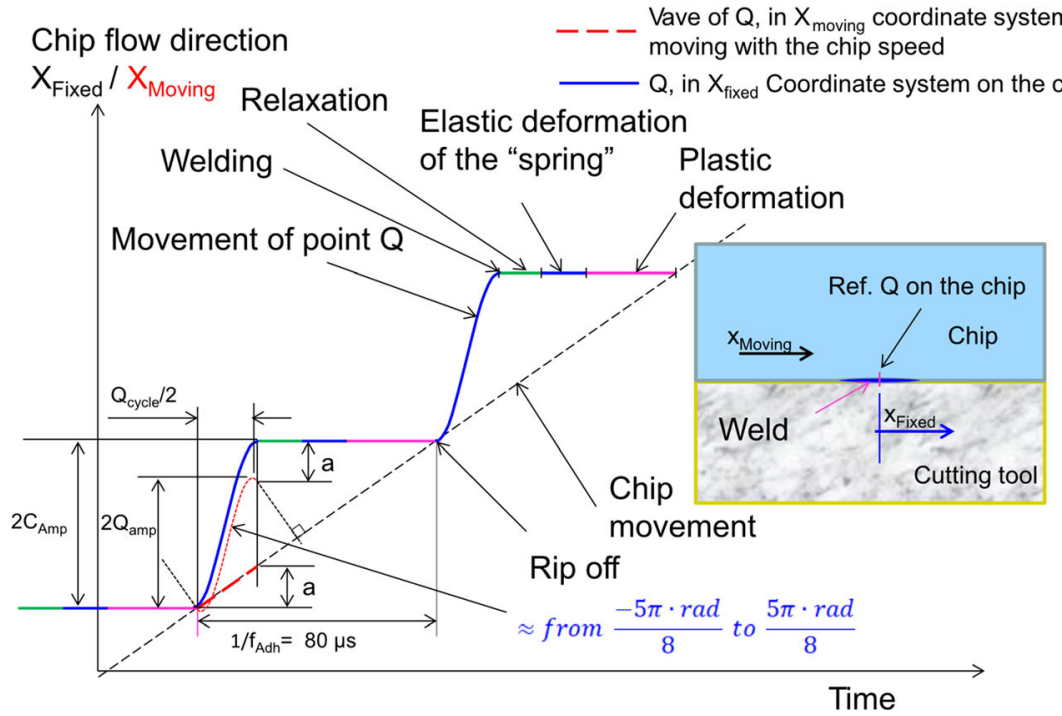

Fig. 13 A quick stop test with the adhesive plastic deformation visible, from the beginning of the wear process, and one of the largest deformations is marked (white curve). The thin zone on the lower side of the chip is a consequence of the adhesive deformation
1 Cycle $=80 \mu \mathrm{s}$

2 Chip travel 0,049 in 1 cycle

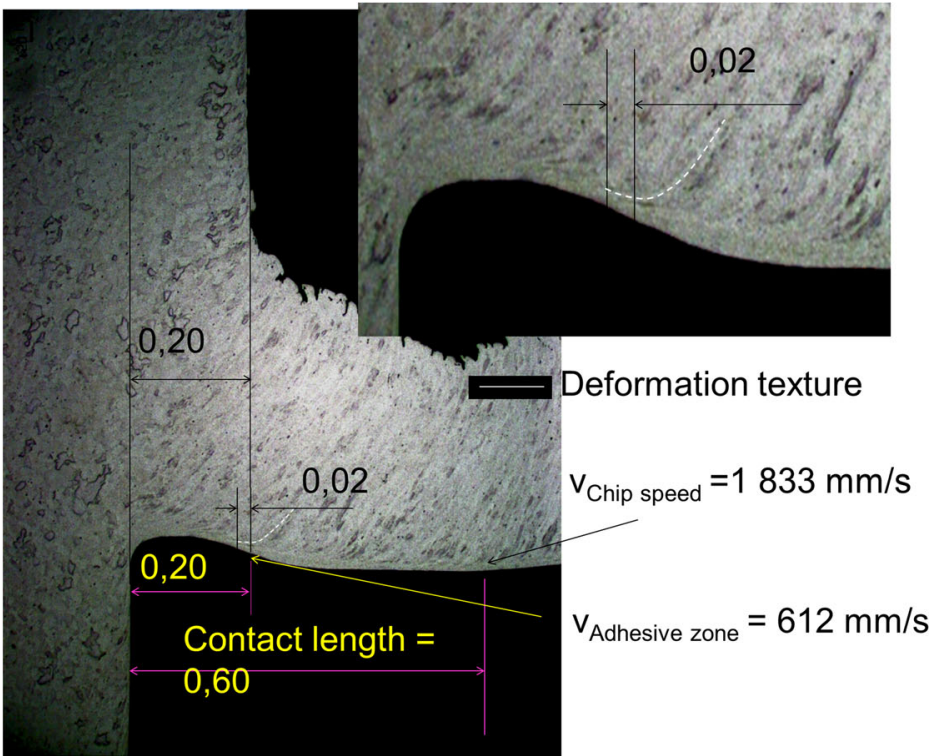


Fig. 14 An increase in amplitude by $50 \%$ compared to the example in Fig. 11

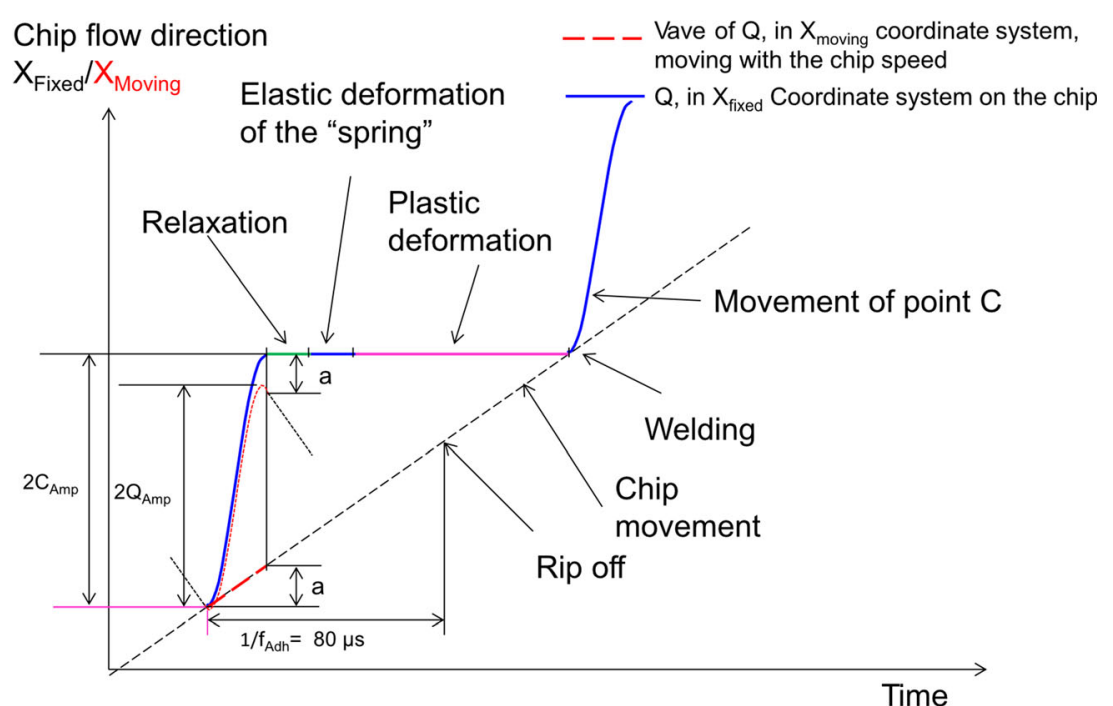

\subsubsection{Adhesive frequency and amplitude}

The first excitation in the cluster generates low amplitude, see Fig. 9. This first cycle causes little or non-plastic deformation, the second more and the third even more which is used in Eq. (2). The coming excitations, numbers 4,5 , and so forth, do not bring anything extra to the amplitudes. The level of vibrations stays at this level. The relative damping in the system is about $8 \%$ and should not cause this limitation.

Using the values in Fig. 12 and making the amplitude of $Q$, $50 \%$ higher, the elastic, $T_{\mathrm{el}}$, and the relaxation, $T_{\text {rel }}$, parts remain in the same size; see Fig. 14. The plastic deformation, $T_{\mathrm{p}}$, has to take up the whole change, an increase of $128 \%$. The plastic resistance is likely not linear. It will take too much force to fulfill its vibration cycle and will therefore decrease in frequency instead.

The frequency will decrease slightly with further engagement; see Figs. 15 and 16, FFT from early in the wear process and after 21 min cutting time. The diagram in Fig. 17 shows amplitude versus cutting speed. The plastic deformation takes a longer time at lower cutting speeds. There is a large portion of stochastic behavior in the appearance of the adhesive wave regarding the frequency, $f_{Q}$, which could be explained by the area of the welding or just the strength of the current welding.

It was a different wear status on the edge for the measurements in Fig. 17. Control measurements were therefore performed with a worn and a sharp edge to see the influence of the wear on the frequency; see Fig. 18. The wear status influences the adhesive cycle frequency to some degree but not as much as the cutting speed. At lower cutting speed, it takes longer to tighten the spring in the dynamic system, and therefore, it vibrates at a lower frequency. The impact of wear is more complex but it is likely so that a larger wear zone gives a larger welded area, more force, and more energy in the dynamic system.
Fig. 15 FFT of the sound signal measured at the cutting time $=3$ min. Amplitude (linear from the microphone in $\mathrm{mV}$ )

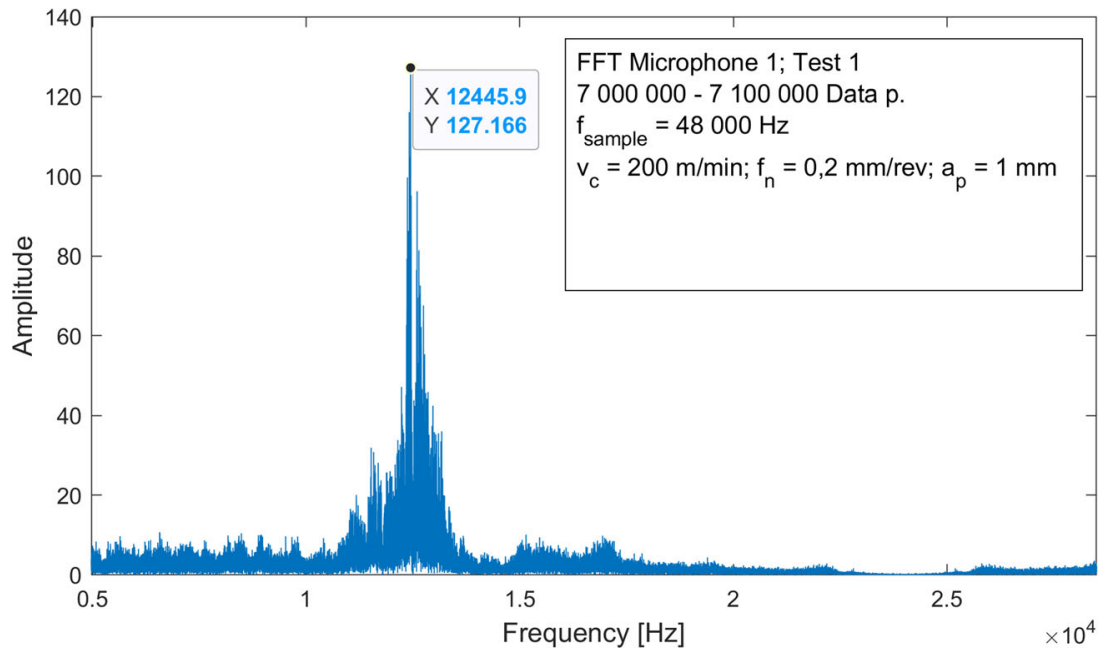


Fig. 16 FFT of the sound signal measured at the cutting time $=21$ $\mathrm{min}$, the frequency drops from about 12.4 to $11.2 \mathrm{kHz}$. Amplitude (linear from the microphone in $\mathrm{mV}$ )

Fig. 17 Adhesive vibration frequency $f_{Q}$ versus cutting speed
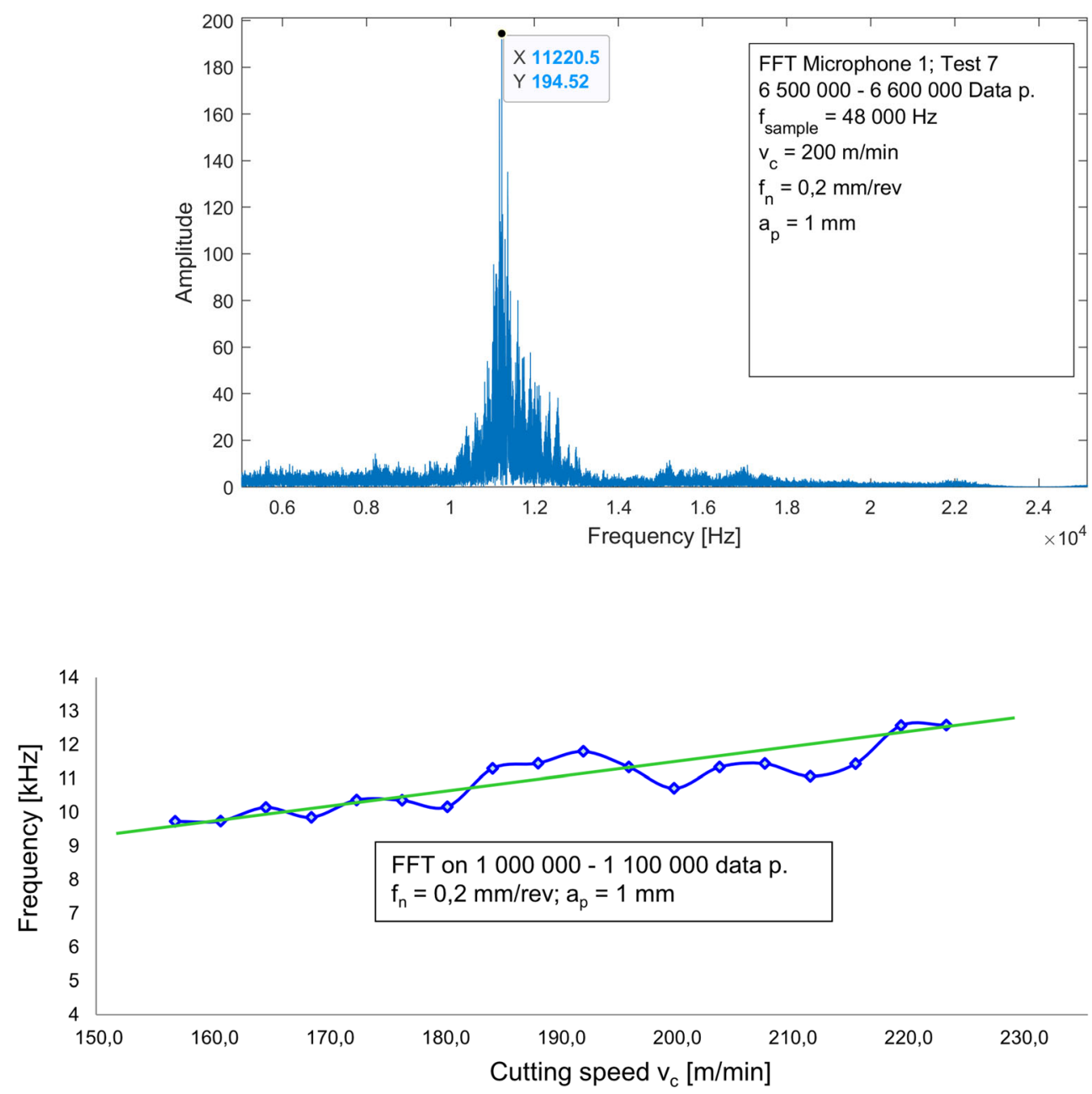

The amplitude increases with wear. The measurements shown in Fig. 19 show a distinct difference. For practical reasons, the measurements are performed at different cutting speeds/workpiece diameters. We have machined with a worn and a new edge, at narrow cutting speeds. Figures 20 and 21 show corresponding FFT for two points in Fig. 19.
Fig. 18 Adhesive frequency $f_{Q}$ versus cutting speed and wear status

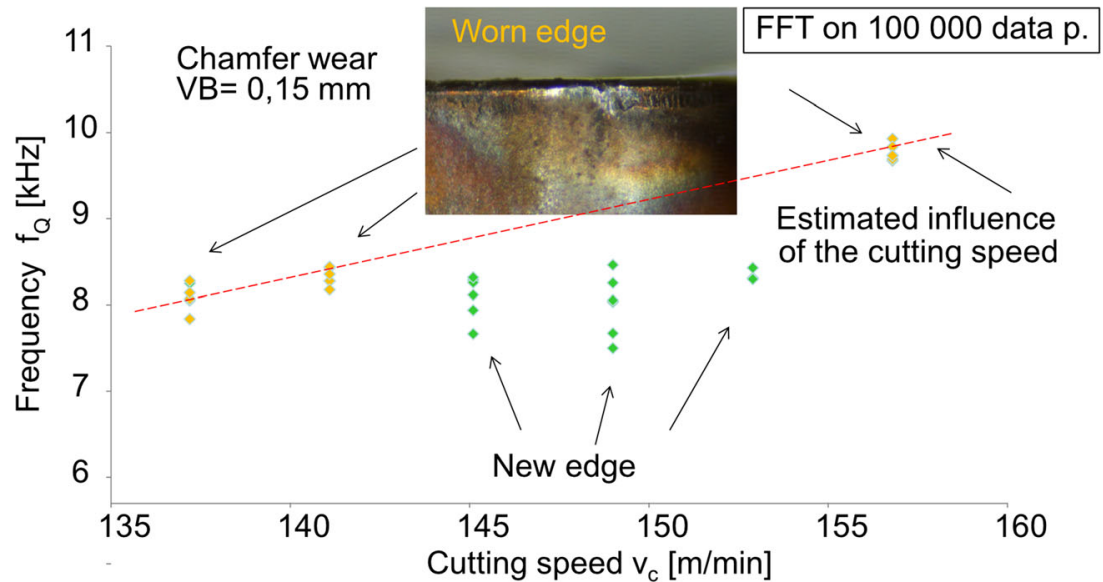


Fig. 19 Adhesive max. amplitude versus cutting speed and wear status. Amplitude (linear from the microphone in $\mathrm{mV}$ )

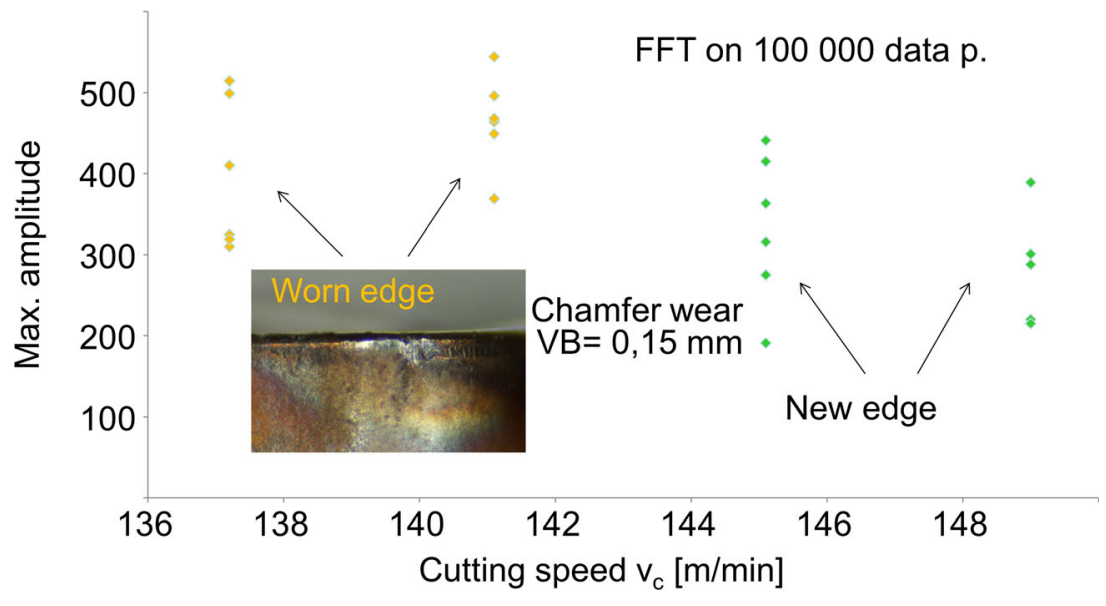

\subsubsection{Adhesive vibration at the beginning of the cut}

Figure 22 shows the beginning of the first cut with an unworn edge. The first adhesions perform clusters with few waves and low amplitude. In this case, it takes about $0.03 \mathrm{~s}$ to develop the adhesion to the picture obtained further on.

Figure 23 shows the same as in Fig. 22 but with a worn edge, after 3 min cutting. In the case with a worn edge, the adhesion starts up more rapidly.

It supports the idea of the necessary degeneration on the cutting tool surface for future welding.

\section{Results and discussion}

\subsection{The mechanism of adhesive wear}

The theoretical analysis and the performed measurements correspond in many aspects well with the presented hypothesis, but still, some questions are not yet answered and more questions can be raised, e.g.,
1. Why does welding occur, what ignites the chemical reaction?

2. How do all other work and cutting tool materials perform?

What have been achieved are:

1. A plausible description of the dynamics in the process. The adhesive vibration is transient including a feedback system limited by the plastic deformation in the chip. The vibration turns out to be a cluster of waves with stochastic duration in time. It starts up again after a stochastic lapse of silence. With current work material and cutting data, a cycle frequency of $12.5 \mathrm{kHz}$ and part of a sine vibration of the chip at the double frequency, i.e., $25 \mathrm{kHz}$, are determined at the beginning of the engagement.

2. The theoretical model predicts that the frequency decrease when the amplitude rises by the wear. This has been verified by the experiments.

3. It has been shown that the adhesive vibrations can be measured through the air, by microphones. The signal archived is both relevant and clean from other disturbance signals.
Fig. 20 FFT of the sound signal measured when cutting with a new edge. Amplitude (linear from the microphone in $\mathrm{mV}$ )

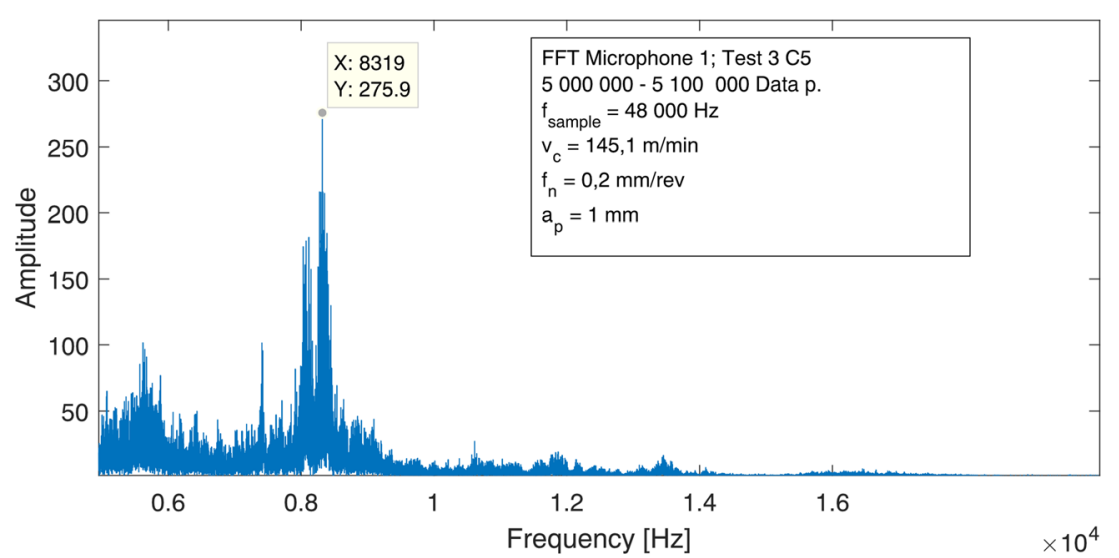


Fig. 21 FFT of the sound signal measured when cutting with a worn edge. Amplitude (linear from the microphone in $\mathrm{mV}$ )

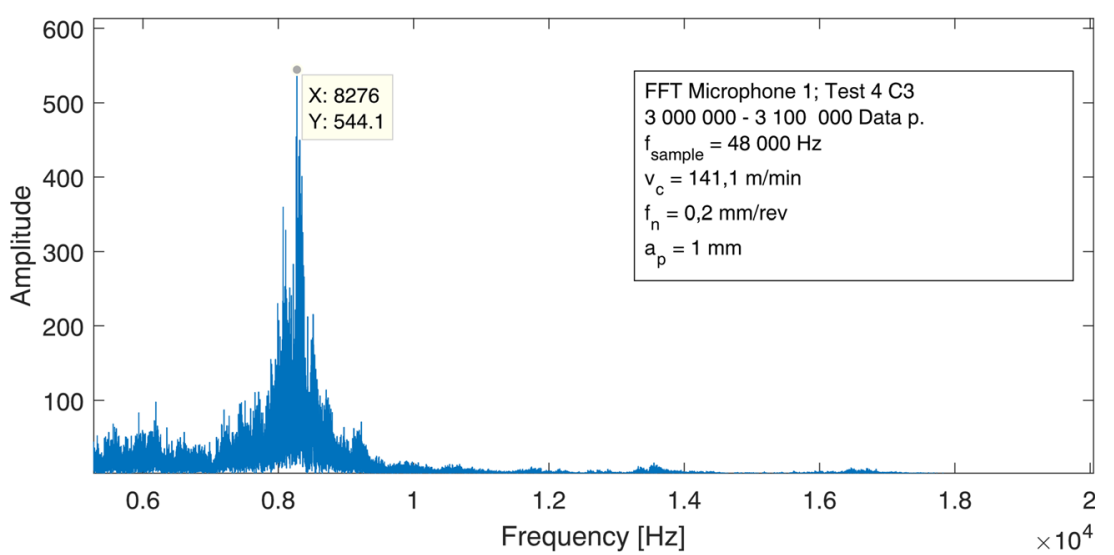

4. The adhesive wear is a removal of thin layers in nanometer range like reversed $3 \mathrm{D}$ printing.

\subsection{Fatigue in the welding zone}

The size of the excitation force on the rake is not known, but it is possible to estimate the adhesive force from the cutting force measurements in Fig. 10; the amplitude is around 25 $\mathrm{N}$. Assuming that the shear strength in the welding zone is about $1000 \mathrm{MPa}$, the welded area ripped off from the cutting tool would be $\mathrm{A}_{1 \mathrm{Ad}} \approx 0,025 \mathrm{~mm}^{2}$.

Assuming further that:

- $\quad$ the amplitude and the ripped of areas are the same on the rake and the clearance sides,
- the adhesive area is $A_{\mathrm{ad}} \approx 0.2 \mathrm{~mm}^{2}$,

- the thickness of the removed materials after $3000 \mathrm{~s}$ machining is $h_{\mathrm{Ad}}=0.005 \mathrm{~mm}$, and

- $3000 \mathrm{~s}$ is about $n_{\text {cycle }} \approx 30$ million cycles (some of the time is without cycles).

Under all these assumptions, the thickness of one adhesive removal would be:

$h_{1, \mathrm{Ad}} \approx \frac{h_{\mathrm{Ad}} \cdot A_{\mathrm{Ad}}}{n_{\mathrm{Ad}} \cdot A_{1, \mathrm{Ad}}}=0.001 \mathrm{~nm}$

The thickness is far less than the diameter of the atoms involved, which is impossible. A more likely explanation of what is happening is that the removal of materials does not occur in every cycle. It is a question of fatigue. It can be so that

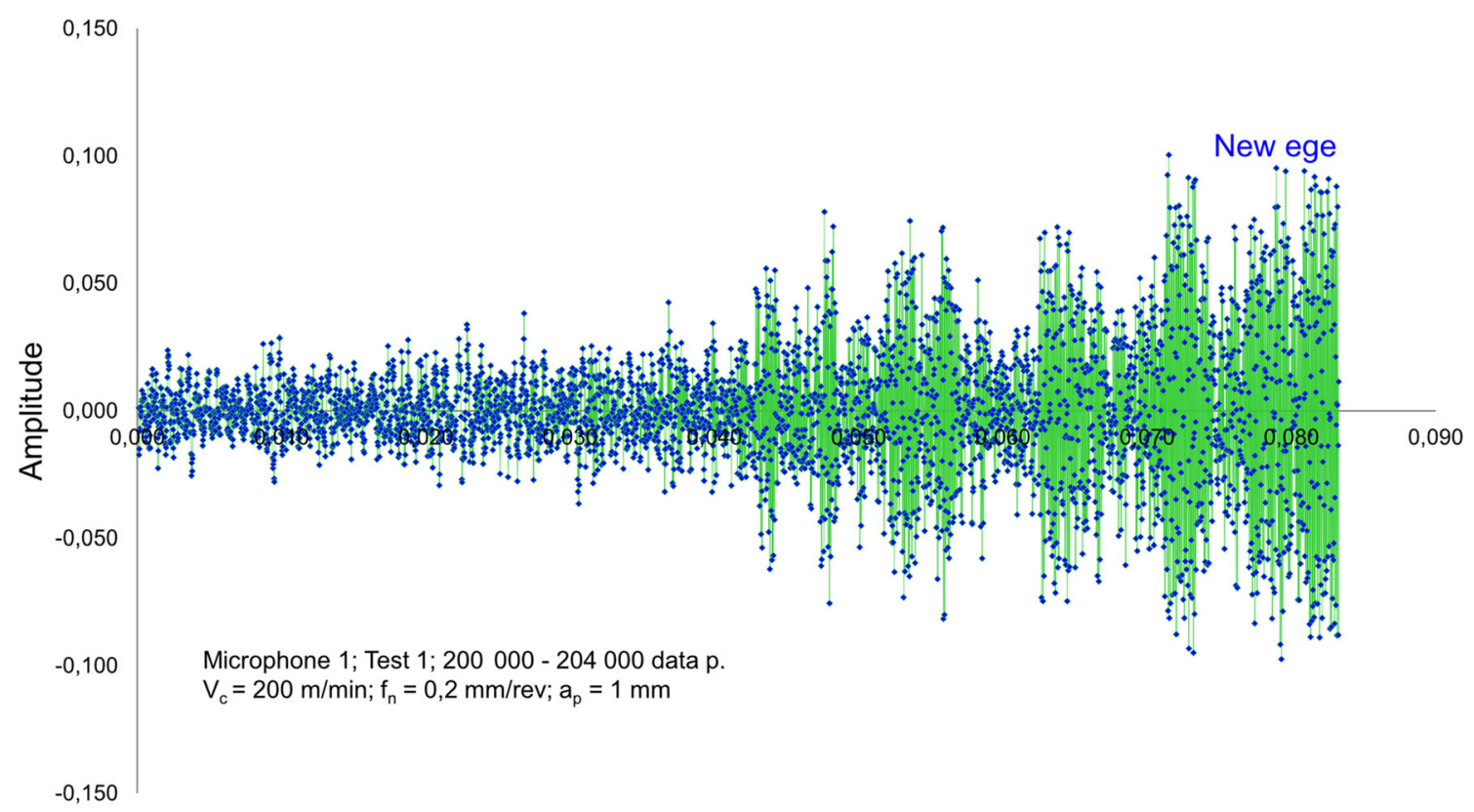

Time [s]

Fig. 22 Adhesive vibration in the beginning of the cut with a new edge, after $0.03 \mathrm{~s}$ cutting. Amplitude (linear from the microphone in $\mathrm{mV}$ ) 


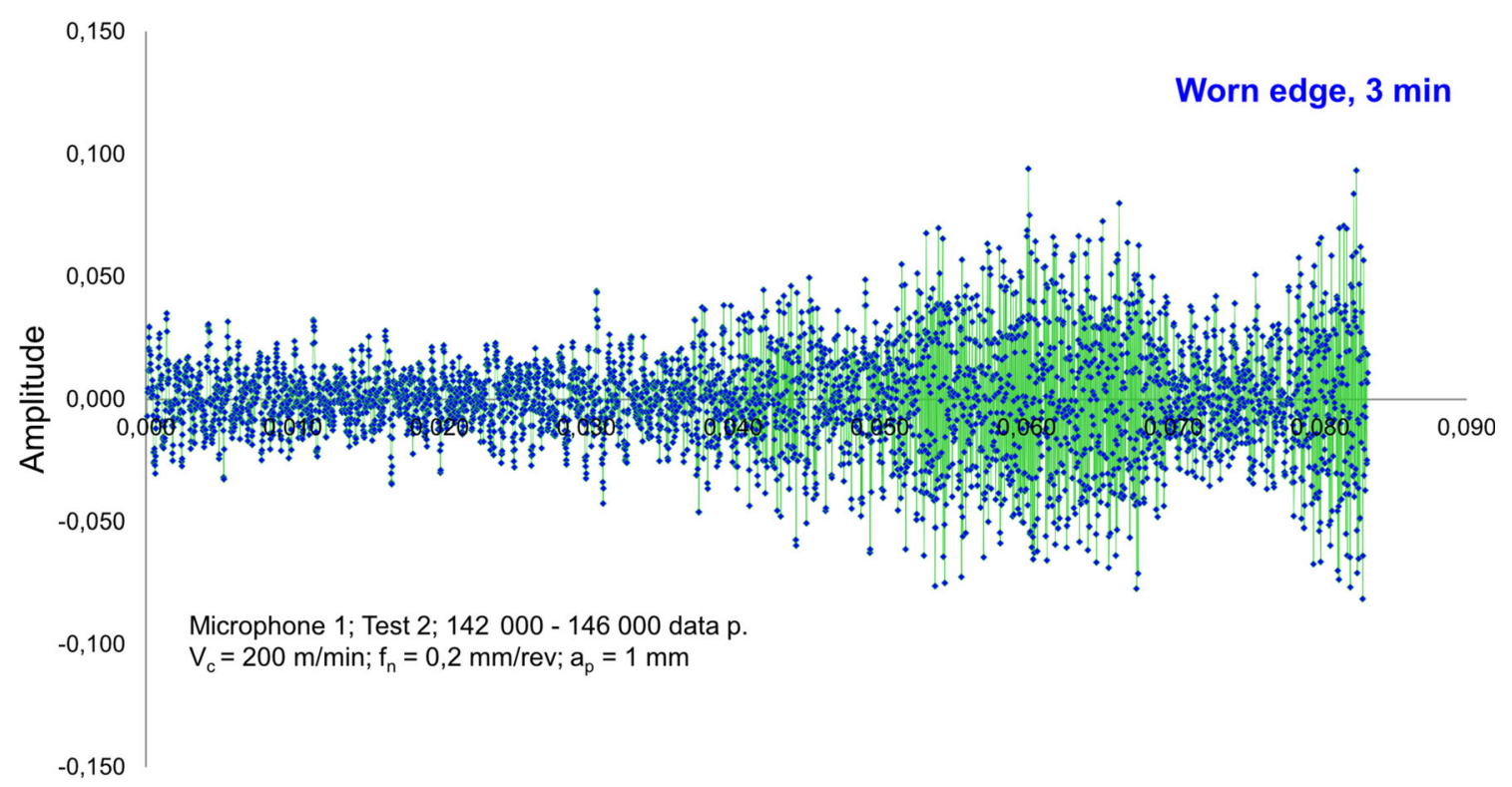

Time [s]

Fig. 23 Adhesive vibration in the beginning of the cut with a worn edge, after 3 min cutting. Amplitude (linear from the microphone in $\mathrm{mV}$ )

all cycles except the last in a cluster lose contact without taking anything away, the fracture is likely one part in the $\mathrm{SiO}$ layer and one part against the cutting tool. The rake face in Fig. 3 shows that pattern. Only the last cycle removes a thin layer of the cutting tool.

\subsection{Possibilities to control or decrease the adhesive wear}

The traditional way is to put something in-between the tool and the chip, like cutting fluid. Cutting fluids are, however, not so environmentally friendly, and it is also difficult to deliver the lubrication where it is most needed; thus, these normally mainly work as coolant, especially at higher cutting speeds [22].

Another way is to add ceramic particles in the work material; they creep out through the chip during the expansion of the chip material on the rake pressing the chip away from the cutting tool rake. The same thing happens when the workpiece surface expands on the clearance of the tool. The mechanism does not prevent the adhesion completely but it decreases the adhesive zone. Almost all metallic materials with few or small ceramic particles are regarded as "sticky" with adhesive wear and deposits on the machined surface. A disadvantage with ceramic particles is that they create abrasive wear. They break in the cutting zone and the fragments, with sharp edges, remove material from the cutting tool [21].

An interesting method used in lead-free free-cutting brass is to inject spherical $\mathrm{Al}_{2} \mathrm{O}_{3}$ particles in the melted brass. The particles are, during the melted stage, transformed to $\mathrm{ZnO}$, which is a tough material, $300 \mathrm{HB}$. They do not break and do not create abrasive wear but they reduce the abrasive zone; see Fig. 24. This lead-free brass is patented with the number SE 135 13 37-9. The same thing can be made in steel but with other particles.

Vibration-assisted machining is also a possibility. If vibrations are generated, forced, in the feed direction on the rake with a frequency, about $20 \%$ higher than the adhesive frequency, $f_{\text {Adh }}$, and an amplitude of about $20-50 \mu \mathrm{m}$, the amplitude will prevent the welding in the same cycles. It will probably not be a big difference but some.

Another solution is to vibrate around $100 \mathrm{kHz}$ with a lower amplitude, 5-10 $\mu \mathrm{m}$. In this case, we get a rake surface standing still for a very short period. The adhesion welding period is probably very short but it must be a limit somewhere.

The last way which is the hardest of them all is to find a coating that can stand the degeneration of the rake

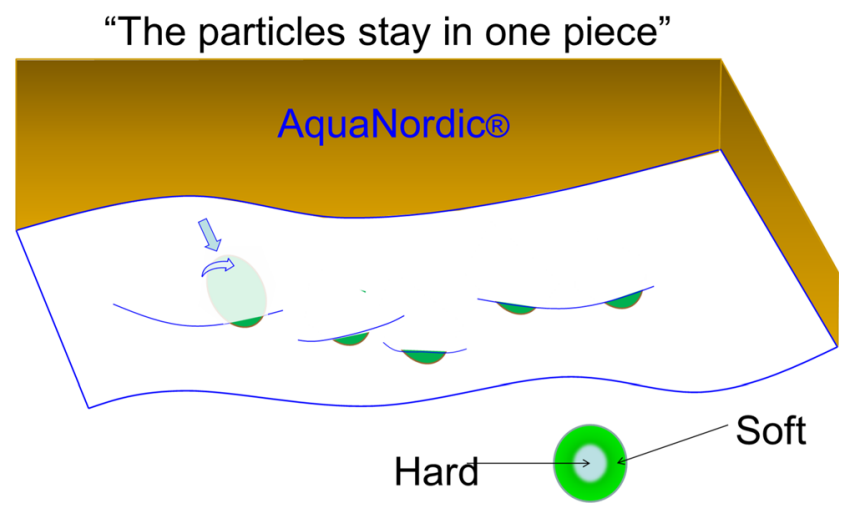

Fig. 24 Ceramic particles, $\mathrm{ZnO}$, in lead-free free-cutting brass 
surface. If we can find such material, then the adhesion is hindered at the start.

\subsection{Monitoring and adaptive control}

The frequency range where adhesive vibrations occur in the type of steel that has been studied is relatively free from other vibration. The signal transmitted by air is easy to pick up and no expensive equipment is needed.

Monitoring the adhesive sound level can be a method for automatic tool wear detection for some work materials and some operations. It is not a general solution. It is likely so that it does not exist any general solutions.

\section{Conclusions}

In this paper, a way to study the adhesive mechanism in turning was revealed, where the adhesive vibration was measured through the acoustic emissions emanating from the vibrating chip.

The presented model explains the wear process as a viscous substance welded to the chip and the rake of the tool and rips off material in an adhesive cycle.

The study resolved significant information about the adhesive frequency in turning that lacks in the published literature and delivered an important conclusion regarding how this frequency changes by the wear status and cutting speed.

The results can be used for the prediction of and or decrease of tool wear. However, this task is complex due to the stochastic behavior of the mechanism.

The theory should be equally applicable to other metal cutting methods for example milling.

The beginning of the metal cutting process and wear conditions is studied and found differences between a worn edge and e new edge regarding the magnitude of adhesive vibrations. This indicates the presence of a degenerated zone on the worn rake. It is shown that an adhesive wear process is a form of fatigue. This is of essential interest in cutting tool material science.

Funding Open access funding provided by University of Gävle.

\section{Declarations}

Competing interests The authors declare no competing interests.

Open Access This article is licensed under a Creative Commons Attribution 4.0 International License, which permits use, sharing, adaptation, distribution and reproduction in any medium or format, as long as you give appropriate credit to the original author(s) and the source, provide a link to the Creative Commons licence, and indicate if changes were made. The images or other third party material in this article are included in the article's Creative Commons licence, unless indicated otherwise in a credit line to the material. If material is not included in the article's Creative Commons licence and your intended use is not permitted by statutory regulation or exceeds the permitted use, you will need to obtain permission directly from the copyright holder. To view a copy of this licence, visit http://creativecommons.org/licenses/by/4.0/.

\section{References}

1. Stephenson D, Agapiou J (2016) Tool wear and tool life. Metal Cutting Theory and Practice, Third Edition, In, pp 529-573

2. Stephenson D, Agapiou J (2016) Surface finish, integrity, and flatness. In: Metal Cutting Theory and Practice

3. Pimenov DY, Guzeev VI, Krolczyk G, Mia M, Wojciechowski S (2018) Modeling flatness deviation in face milling considering angular movement of the machine tool system components and tool flank wear. Precis Eng 54:327-337. https://doi.org/10.1016/j. precisioneng.2018.07.001

4. Maruda RW, Krolczyk GM, Wojciechowski S, Powalka B, Klos S, Szczotkarz N, Matuszak M, Khanna N (2020) Evaluation of turning with different cooling-lubricating techniques in terms of surface integrity and tribologic properties. Tribol Int 148:106334. https:// doi.org/10.1016/j.triboint.2020.106334

5. Liew PJ, Shaaroni A, Sidik NAC, Yan J (2017) An overview of current status of cutting fluids and cooling techniques of turning hard steel. Int J Heat Mass Transf 114:380-394. https://doi.org/10. 1016/j.ijheatmasstransfer.2017.06.077

6. Yamamoto T, Buckley DH (1982) Wear mechanism based on adhesion, NASA Thechnical Paper 2037. Cleveland

7. Kümmel J, Braun D, Gibmeier J, Schneider J, Greiner C, Schulze V, Wanner A (2015) Study on micro texturing of uncoated cemented carbide cutting tools for wear improvement and built-up edge stabilisation. J Mater Process Technol 215:62-70. https://doi. org/10.1016/j.jmatprotec.2014.07.032

8. Zhang K, Deng J, Sun J, Jiang C, Liu Y, Chen S (2015) Effect of micro/nano-scale textures on anti-adhesive wear properties of $\mathrm{WC} /$ Co-based TiAIN coated tools in AISI 316 austenitic stainless steel cutting. Appl Surf Sci 355:602-614. https://doi.org/10.1016/j. apsusc.2015.07.132

9. Choudhury I, El-Baradie M (1998) Tool-life prediction model by design of experiments for turning high strength steel (290 BHN). J Mater Process Technol 77:319-326. https://doi.org/10.1016/s09240136(97)00435-4

10. Tatar K, Sjöberg S, Andersson N (2020) Investigation of cutting conditions on tool life in shoulder milling of Ti6Al4V using PVD coated micro-grain carbide insert based on design of experiments. Heliyon 6. https://doi.org/10.1016/j.heliyon.2020.e04217

11. Liu N, Zheng C, Xiang D, Huang H, Wang J (2019) Effect of cutting parameters on tool wear under minimum quantity cooling lubrication (MQCL) conditions. Int J Adv Manuf Technol 105: 515-529. https://doi.org/10.1007/s00170-019-04259-z

12. Wojciechowski S, Talar R, Zawadzki P, Wieczorowski M (2020) Evaluation of physical indicators and tool wear during grooving of spheroidal cast iron with a novel WCCo/cBN (BNDCC) inserts. Wear 454-455:203301. https://doi.org/10.1016/j.wear.2020. 203301

13. Klaasen H, Kübarsepp J, Roosaar T, Viljus M, Traksmaa R (2010) Adhesive wear performance of hardmetals and cermets. Wear 268: 1122-1128. https://doi.org/10.1016/j.wear.2010.01.006

14. Hase A, Mishina H, Wada M (2012) Correlation between features of acoustic emission signals and mechanical wear mechanisms. Wear 292-293:144-150. https://doi.org/10.1016/j.wear.2012.05. 019 
15. Song J, Liu T, Shi H, Yan S, Liao Z, Liu Y, Liu W, Peng Z (2017) Time-frequency analysis of the tribological behaviors of Ti6Al4V alloy under a dry sliding condition. J Alloys Compd 724:752-762. https://doi.org/10.1016/j.jallcom.2017.07.097

16. Hase A, Mishina H (2009) Wear elements generated in the elementary process of wear. Tribol Int 42:1684-1690. https://doi.org/10. 1016/j.triboint.2009.02.006

17. Pham-Ba S, Brink T, Molinari JF (2020) Adhesive wear and interaction of tangentially loaded micro-contacts. Int J Solids Struct 188-189:261-268. https://doi.org/10.1016/j.ijsolstr.2019.10.023

18. Ptáček P, Frajkorová F, Šoukal F, Opravil T (2014) Kinetics and mechanism of three stages of thermal transformation of kaolinite to metakaolinite. Powder Technol 264:439-445. https://doi.org/10. 1016/j.powtec.2014.05.047
19. Vik R (2018) Testprocedur för undersökning av adhesiv förslitning vid svarvning. University of Gävle

20. Weck M, Teipel K (1977) Dynamisches Verhalten spanender Werkzeugmaschinen. Springer, Berlin Heidelberg, Berlin, Heidelberg

21. Svenningsson I (2017) On the mechanism of two-body abrasive wear in turning "the spin-split theory." Int J Adv Manuf Technol 92:3337-3348. https://doi.org/10.1007/s00170-017-0259-4

22. Stephenson D, Agapiou J (2016) Mechanics of cutting. Metal Cutting Theory and Practice, Third Edition, In, pp 393-447

Publisher's note Springer Nature remains neutral with regard to jurisdictional claims in published maps and institutional affiliations. 